\title{
Cultura Cafeeira no Norte do Paraná e suas Marcas nas Paisagens: potencialidades para o turismo
}

\author{
The Coffee Cultivation in the North of Paraná and its Marks in the Landscapes: \\ potentialities for tourism
}

\author{
La Cultura Cafetera en Norte del Paraná y sus huellas en los paisajes: \\ potencialidades para el turismo
}

Alini Nunes de Oliveira ${ }^{1}$

\begin{abstract}
RESUMO: Dentre as regiões brasileiras de destaque na produção cafeeira, o estado de São Paulo e o Paraná (em especial as regiões Norte Central e Norte Pioneiro) foram marcados ao longo de sua história pela grande produção deste grão. O presente artigo tem como objetivo traçar um panorama da cultura cafeeira no Brasil e, na sequência, como se desenvolveu no estado do Paraná, além de apresentar marcas da cafeicultura em algumas paisagens de propriedades rurais do Norte do Paraná, que integram a Rota do Café e suas potencialidades para o turismo. Como procedimentos metodológicos adotados estão a pesquisa bibliográfica e documental, além do trabalho de campo, instrumento fundamental para este tipo de pesquisa, já que auxilia na produção de informação empírica. O norte do Paraná apresenta elementos nos quais o café remete à sua história pela importância socioeconômica que exerceu e pode-se observar em algumas paisagens as marcas deixadas por este tempo importante para a população norte paranaense. Assim, em algumas paisagens é possível perceber as marcas deixadas pela cafeicultura, sendo a valorização da cultura cafeeira como atrativo turístico um dos principais objetivos da Rota do Café.
\end{abstract}

PALAVRAS-CHAVE: Paisagem. Café. Norte do Paraná.

\begin{abstract}
Among the Brazilian regions that have a prominent of coffee production, São Paulo and Paraná States (in particular the North Central area and Pioneer North region) were marked throughout their history by a large production of this crop. This article aims to provide a picture of the coffee cultivation in Brazil and, in the aftermath, it has developed in the Paraná State, besides presenting marks from coffee culture in some rural properties' landscapes in the North of Paraná State, that integrate the Coffee Route and its potentialities for tourism. As methodological procedures adopted in this paper are bibliographic and documentary research, in addition to field work, a fundamental instrument for this type of research, since it helps in the production of empirical information. The North of Paraná State presents elements linked to its history by the socio-economic importance that it had and the marks left by this important time to the population from North of Paraná can be noted in some landscapes. Thus, in some landscapes from North of Paraná State it's possible to realize the marks left by coffee culture, and the valorization of coffee culture as tourist attraction is one of the main objectives of Coffee Route.
\end{abstract}

\footnotetext{
1 Universidade Federal do Paraná - UFPR. Avenida Sete de Setembro, 2645 - 3o andar - Edifício Teixeira Soares - Curitiba/PR. CEP: 80060-140. E-mail: alini_oliveira@hotmail.com.
} 
KEYWORDS: Landscape. Coffee. North of Paraná.

RESUMEN: Entre las regiones brasileñas de destaque en la producción cafetera, el estado de São Paulo y Paraná (en especial la región Norte Central y Norte Pionero) fueron marcados a lo largo de su historia por la gran producción de este grano. El presente artículo tiene como objetivo delinear un panorama de la cultura cafetera en Brasil y, posteriormente, como esta investigación se desarrolló en el estado del Paraná, además de presentar huellas de la cafeticultura en algunos paisajes de propiedades rurales del Norte del Paraná, que integran la Ruta del Café y sus potencialidades para el turismo. Como procedimientos metodológicos adoptados en este artículo, la investigación bibliográfica y documental, además del trabajo de campo, es un instrumento fundamental para este tipo de investigación, ya que ayuda en la producción de información empírica. El Norte del Paraná presenta elementos en los que el café alude a su historia por la importancia socioeconómica que ejerció y se puede observar en algunos paisajes las huellas dejadas por este tiempo importante para la población norte paranaense. Así, en algunos paisajes del Norte del Paraná es posible notar las huellas dejadas por la cafeticultura, siendo la valoración de la cultura cafetera como atractivo turístico es uno de los principales objetivos de la Ruta del Café.

PALABRAS CLAVE: Paisaje. Café. Norte del Paraná.

\section{INTRODUÇÃO}

Além da diversidade de povos, culturas e paisagens, o Brasil é um grande produtor de alimentos e possui destaque tanto na quantidade quanto na qualidade da produção de café. O país tem condições climáticas que favorecem o cultivo do café em 15 regiões produtoras (BRASIL, 2017) e, devido à sua diversidade de clima, relevo e tipos de solo, é possível o cultivo destes grãos com variados padrões de qualidade e aromas, entre as duas espécies cultivadas, o café Arábica e o café Conilon.

Principalmente a partir do século XIX, o Brasil passa a ter maior dinamismo na economia, com a demanda de um mercado consumidor mundial à espera da produção cafeeira. O Brasil passou a ser destaque nas regiões tropicais, devido às condições climáticas e morfológicas, chegando a 75\% da produção mundial (ROSANELI, 2013).

Dentre as áreas brasileiras de destaque na produção cafeeira, o estado de São Paulo e o Paraná (em especial a região Norte Central - também conhecido a como Norte Novo - e o Norte Pioneiro, também conhecido como Norte Velho) foram marcados ao longo de sua história pela produção deste grão, figurando-se como produtor e exportador de café a partir do início do século XX.

A valorização da cultura cafeeira por meio do turismo permite aprofundar os laços dos norte-paranaenses com a história do café por meio da ressignificação de seu patrimônio, ao mesmo tempo em que, aos turistas, permite uma oportunidade de conhecimento de paisagens e da cultura local, considerando a paisagem em suas várias dimensões: 
morfológica, funcional, histórica, especial e, fundamentalmente por ser turística, na sua dimensão simbólica.

O presente artigo tem como objetivo traçar um panorama da cultura cafeeira no Brasil e, na sequência, como se desenvolveu no estado do Paraná, além de apresentar as marcas da cafeicultura em algumas paisagens de propriedades rurais do Norte do Paraná, que integram a Rota do Café. Além da pesquisa bibliográfica e documental, um dos procedimentos adotados nesta pesquisa foi o trabalho de campo, instrumento fundamental para este tipo de pesquisa, já que permite a aproximação do objeto de estudo e para a produção de informação empírica.

\section{A CULTURA CAFEEIRA NO BRASIL}

Milton Santos e Maria Laura Silveira (2005) relatam a realidade vivida pelo Brasil a partir da década de 1960, quando se intensifica a modernização da agricultura brasileira, com inovações técnicas e organizacionais (sementes geneticamente modificadas, agroquímicos, culturas de entressafra, créditos públicos específicos etc.), criando um novo uso do tempo e da terra. Criam-se "cinturões" (áreas especializadas de produção) e fronteiras agrícolas que passaram a privilegiar as culturas de exportação (como soja, milho e trigo), em detrimento das culturas vinculadas à alimentação básica tradicional (arroz, feijão e mandioca, só para citar alguns). Inclusive os autores tratam de uma "modernização em manchas", com áreas descontínuas e especializadas em certos produtos, ocorrendo um "[...] conflito velado entre a agricultura de exportação e a agricultura para o mercado interno [...]" (SANTOS; SILVEIRA, 2005, p. 120).

Segundo estes autores, nesta época, nas regiões tradicionais o café perdeu consideravelmente o volume de produção para outras culturas de maior destaque mundial, sendo que em 1960 a produção nacional era de aproximadamente 4 milhões de toneladas, passando para 2 milhões em 1980.

Até a década de 1940, o café praticamente se restringia aos estados de São Paulo, Minas Gerais, Espírito Santo, Rio de Janeiro e Paraná, concentrando cerca de $96 \%$ dos hectares destinados a este produto. Entre as décadas de 1940 e 1960 o Paraná se destaca com o aumento da área de produção (passando de 5,27\% para 30,22\% da área total do país).

Porém, a partir da década de 1970, há um veloz decréscimo na área plantada do estado do Paraná, em favor de outros produtos, o que acontece também com o estado de São Paulo, dois estados tradicionalmente produtores de café. Em paralelo a isso, a partir desta década, outras frentes pioneiras (como Rondônia, oeste da Bahia, algumas áreas de Mato Grosso, Goiás e Pará) incorporam-se à produção nacional, sendo que diferentes 
condições de ordem natural (solo, clima e relevo, por exemplo), técnicas (máquinas, logística e tecnologia aplicada, entre outras) e organizacional (impostos, normas regulatórias locais etc.) conferem, a cada região, uma produtividade espacial específica (SANTOS; SILVEIRA, 2005).

Nos estados de Espírito Santo e Minas Gerais, apesar de produzirem café desde a segunda metade do século XIX, foi apenas a partir da década de 1970 que estes passaram a ser grandes produtores, pois as lavouras se espalharam por áreas de cerrado (Minas Gerais e oeste baiano em seguida) e áreas montanhosas (sul de Minas e Espírito Santo). Este processo se dá por dois principais fatores: expansão da fronteira agrícola moderna e política de renovação da cafeicultura (FREDERICO, 2014).

Segundo Ortega e Jesus (2011) com o objetivo de erradicar os cafezais considerados de baixa produtividade de regiões tradicionais sujeitas a geadas (como o norte do Paraná e o oeste de São Paulo) e a implantação de novas variedades em áreas consideradas mais apropriadas, foi implementado o Plano de Renovação e Revigoramento dos Cafezais (PRRC), como parte da política de modernização da cafeicultura brasileira, iniciada em 1969.

Até o final da década de 1990 existiam várias organizações que regulavam o mercado cafeeiro mundial, como a Organização Internacional do Café (OIC). Por meio delas a produção cafeeira então era regida por acordos, como os Acordos Internacionais do Café (AIC), estipulados entre países produtores e importadores com o objetivo de definir preços, cotas de exportação e importação e quantidade de estoques.

Porém, desde o início da década de 1990, a cafeicultura nacional passou a conviver com o processo de desregulamentação do setor. O fim dos acordos, em 1989, causou uma instabilidade internacional e representou o início de uma disputa entre países e regiões produtoras, em busca de maior representação na comercialização do grão (FREDERICO, 2014). Nesta época, muitos institutos nacionais do café foram extintos (a exemplo do Instituto Brasileiro, em 1990) e os preços pagos pelo café tiveram uma queda brusca. Segundo Frederico (2014, p. 57-58) o que contribuiu para a baixa dos preços do café foi "[...] a extinção dos estoques reguladores em poder dos países produtores [...] e 0 aumento da competitividade entre os países e regiões produtoras [...]".

A partir daí a produção cafeeira passa a se reerguer, mas com características diferentes de períodos anteriores, considerada por Frederico (2014) como cafeicultura científica globalizada. Em sua análise, Frederico (2014) salienta que a modernização e a expansão agrícola têm levado as regiões a se especializarem, conferindo uma maior eficiência produtiva, com intuito de serem competitivas no mercado internacional. Também explica que diversos fatores contribuíram para a expansão e a consolidação da cafeicultura 
em áreas de montanha (como Espírito Santo e Minas Gerais) a partir da década de 1970: fatores climáticos adversos (geadas no Paraná e São Paulo); a elevação da renda da terra e a concorrência com outras culturas (como a soja, cana-de-açúcar e laranja), que contribuíram para a diminuição da produção cafeeira nestes estados; assim como condições naturais favoráveis de clima, solo, relevo e disponibilidade de água, preço da terra relativamente baixo, disponibilidade de mão de obra e apoio técnico e financeiro de políticas estatais. Estes fatores explicam a diminuição da produção cafeeira do Paraná e o seu destaque nas regiões de altitudes mais elevadas.

Em 2018 o Brasil manteve sua posição de maior produtor e exportador mundial de café (EMBRAPA, 2019), com destaque para o estado de Minas Gerais, seguido de Espírito Santo (COMPANHIA NACIONAL DE ABASTECIMENTO, 2019). A produção de café brasileira tem sido expressiva tanto para exportação quanto para o consumo interno (CONSELHO DOS EXPORTADORES DE CAFÉ DO BRASIL, 2019). Segundo uma pesquisa solicitada pela ABIC (Associação Brasileira da Indústria de Café), em parceria com o Consórcio Pesquisa Café e coordenado pela Embrapa Café, realizada no período de novembro de 2013 a outubro de 2014, o café era a segunda bebida mais consumida no Brasil (em primeiro lugar, a água) (EMPRAPA, 2015).

Para compreender o desenvolvimento da economia do Paraná alicerçado na cultura cafeeira, mais especificamente da região norte do estado, é importante mencionar sua história e ocupação.

\section{A CULTURA CAFEEIRA NO PARANÁ}

A ocupação territorial do estado do Paraná se fez concomitantemente com sua exploração econômica a partir do século XVI. Duas correntes colonizadoras, a portuguesa pelo litoral e a espanhola pelo Oeste, foram responsáveis pelos primeiros povoamentos. No final do século XVI a atividade mineradora (ouro) se expande e a ocupação do território é mais intensa, com a fundação de núcleos em Paranaguá, Antonina e Curitiba. Junto com a mineração, uma agricultura incipiente começa a despontar com o intuito de abastecer os povoados (ALMEIDA, 1981).

Nas últimas décadas do século XVII, quando o ouro se esgota, a agricultura de subsistência toma mais áreas do território. No final do século XVII e início do século XVIII Minas Gerais torna-se um polo atrativo por conta do ouro descoberto na região. Para ser escoada a produção até os centros exportadores, necessitava-se de transporte de cargas, que na ocasião era o lombo dos animais (principalmente muares), estimulando o comércio de animais. Desta forma, outra atividade começa a se tornar importante no planalto paranaense: a pecuária, multiplicando as fazendas de criação. A atividade foi destaque no 
Paraná até 1881, entrando em declínio e, após um período de estagnação, outro produto agrícola passa a se destacar na região: o mate, planta nativa do sul do Paraná, com objetivo de exportação para o mercado argentino e chileno (ficando até 1914, quando há um declínio em sua rentabilidade, pois o Paraguai entra para competir no mercado). Em meados do século XIX, outra atividade também importante foi a extração de madeira que, desde o início da colonização, serviu para abastecer o mercado interno, dada a vasta floresta de araucárias.

Até a década de 1930 o Paraná ainda possuía uma economia periférica e dependente de São Paulo. A partir daí é que o estado vê um novo surto de crescimento: o café transforma o perfil da economia e também a estrutura de ocupação territorial. É também a partir deste período que o norte do estado alcança significado na economia, com a agricultura do café. Segundo Almeida (1981), a evolução de toda a região norte se confunde, muitas vezes, com a evolução da economia cafeeira. Pela forte influência da realidade paulista, Cancian (1981) menciona que a marcha para o oeste paulista adentrou as terras paranaenses em busca de novas terras, destacando-se, assim, a cafeicultura.

A ocupação mais efetiva do território do norte do Paraná se dá ao final do século XIX, na área onde hoje se localizam os municípios de Jacarezinho, Santo Antônio da Platina, Cambará etc. (chamado de Norte Velho ou Pioneiro). Pela estreita ligação com São Paulo, paulistas e mineiros passaram a ocupar estas áreas com o objetivo de formar fazendas para o cultivo do café. O estado de São Paulo encontrava-se, neste período, já em declínio nas áreas tradicionais produtoras, enfrentando problemas de esgotamento do solo, doença nos cafezais e urbanização. Principalmente o Norte Pioneiro apresentava ótimas condições para o desenvolvimento desta atividade: fertilidade do solo, terras ainda a serem ocupadas, preços baixos e apoio do governo a empresas particulares com o objetivo de sistematizar a ocupação (já que até então dava-se de forma desordenada) (ALMEIDA, 1981). Segundo Padis (2006), a ocupação do norte do estado foi tão rápida e feita de maneira tão desordenada que o presidente da província passou a estabelecer normas para regulamentar esta ocupação em 1892.

Dos empreendimentos colonizadores que se instalaram na região norte do estado, o mais notável foi a Companhia Melhoramentos Norte do Paraná (CMNP), na origem de capital inglês. A ideia inicial deste grupo saindo da Inglaterra com destino ao Brasil foi investir em atividades agrícolas brasileiras. Após visitar várias regiões do país, ao conhecer terras paranaenses, esta companhia comprou extensas áreas de terras para instalar fazendas de algodão e máquinas de beneficiamento de café, organizando assim em Londres a Brazil Plantations Syndicate Ltda. Não houve sucesso no plano inicial, então criaram um empreendimento imobiliário, a Paraná Plantation, cuja subsidiária brasileira se chamou Companhia de Terras Norte do Paraná (CTNP) (ALMEIDA, 1981; CESÁRIO, 1991; 
HOFF, 1991; PADIS, 2006), companhia que exerceu a maior influência na região conhecida hoje como Norte Novo do Paraná (CESÁRIO, 1991). O sucesso da colonização foi tão grande que, na década de 1930, outro projeto foi iniciado, na região chamada de Norte Novíssimo. Além desta companhia, outras duas foram importantes para a ocupação da região Norte do Paraná (ambas de capital japonês): a Brazil Tokushoku Kaisha e a Nambei Tochikubushiri, onde hoje estão localizados os municípios de Assaí e Uraí. Porém, nestes dois casos, o foco não era o plantio do café, mas sim do algodão (PADIS, 2006).

Importante salientar que um dos fatores que distinguiu a ocupação do Norte Novo em relação ao Norte Velho foi seu caráter induzido (CESÁRIO, 1991). O território do Norte Novo, terras adquiridas pelas companhias colonizadoras, foi dividido em zonas de ocupação e tinha o apoio do governo do estado. Estas zonas foram divididas em glebas, buscando-se também a instalação de núcleos de apoio às propriedades rurais (chamados de "patrimônios"), não distando mais de 15 quilômetros entre uma propriedade rural e um patrimônio. Esta forma de ocupação contribuiu com a rápida urbanização do Norte Novo, com a formação de uma rede urbana com cidades muito próximas umas às outras que desenvolveram funções administrativas e de serviços diversificados.

Cesário (1991) ressalta também a dinâmica diferenciada do Norte Novo em relação ao Norte Velho quando se trata da produção e do beneficiamento do café. No Norte Novo, os sítios e os bairros rurais eram espaços importantes para a produção cafeeira e para o modo de vida rural, mas o beneficiamento se dava nos núcleos urbanos. Já no Norte Velho, o beneficiamento do café ocorria geralmente na própria fazenda, pois grande parte delas contava com equipamentos para a transformação dos grãos.

Com a divulgação da cultura cafeeira e das terras do norte do Paraná, mais pessoas passam a investir na região, já que em São Paulo se encontravam muitos cafeeiros velhos que produziam a custos elevados.

Para o sucesso da ocupação da região e incremento na produção, foi necessário o investimento em estradas, que ligassem o estado de São Paulo às terras adquiridas pelas companhias e colocadas à venda. Para incrementar ainda mais a produção e viabilizar preços mais competitivos, em 1924 são iniciados os primeiros trabalhos de implantação de uma ferrovia ligando o norte do estado ao porto de Paranaguá. Nesta época já havia uma ligação do norte do Paraná com a estrada de ferro Sorocabana, indo até Ourinhos (CANCIAN, 1981). Segundo Padis (2006), a estrada de ferro e a rodovia entrelaçavam os diversos núcleos urbanos que passaram a surgir na região, próximos uns aos outros.

Apesar das dificuldades conjunturais no país, o Paraná procurou atrair o café, pois era o produto que mais representava divisas e era o produto agrícola mais defendido pelo governo na época. Os cafeicultores no Paraná, diferentemente de São Paulo, não se especializaram em monocultura de grandes propriedades. Desenvolveram-se em pequenas 
e médias propriedades que, além do café, também investiram em pastagens, algodão e lavouras temporárias (CANCIAN, 1981; PADIS, 2006). Além disso, o proprietário (antigo colono) e a família eram parte da mão-de-obra empregada que trabalhava na terra, diminuindo os custos de produção. E mesmo para os casos de propriedades um pouco maiores, tinham pequeno número de colonos ou parceiros. Segundo Cancian (1981, p. 46), “Todo Norte do Paraná foi dominado por verdadeiro mar de cafezais, até meados da década de 1960 [...].

Padis (2006) também relaciona o tamanho das propriedades e a forma de trabalho empregado com o tipo de economia desenvolvida na região, ou seja, a força de trabalho da família, em muitos casos, era suficiente para suprir a demanda de mão de obra e a produção exigia um volume de capital não muito alto.

Do início do século XX até a década de 1970, a área cafeeira paranaense foi se ampliando, do Norte para o noroeste, até atingir o extremo oeste, localizando-se quase que inteiramente no Terceiro Planalto. No início era formada apenas pelo Norte Pioneiro (até Jacarezinho), e em meados da década de 1920 estende-se para a microrregião de Assaí. $\mathrm{Na}$ década de 1930 inaugura-se uma nova etapa na expansão dos cafezais, quando a colonização passa a atingir o Norte Novo, microrregião de Londrina. Entre fins de 1930 e início da década de 1940, expande-se para as microrregiões de Apucarana e Maringá. O pós-guerra intensificou o plantio de café e atingiu também o Norte Novíssimo, em que se engloba Paranavaí, Umuarama e imediações, chegando na década de 1960 até o extremo oeste, quase na fronteira com o Paraguai, mas já em pequena escala.

Segundo Cancian (1981), a cafeicultura paranaense se processou em três fases: 1) no Norte Velho (ou Pioneiro), da divisa com o estado de São Paulo até o rio Tibagi, do final do século XIX até 1929; 2) no Norte Novo, do Rio Tibagi, passando por Londrina, até o rio Ivaí, a partir da década de 1930, até o final da Segunda Guerra Mundial; e 3) no Norte Novíssimo, do rio Ivaí até o rio Piquiri, e deste até o rio Iguaçu, no Extremo Oeste, entre as décadas de 1940 e 1960, quando se encerra o expansionismo cafeeiro no Paraná.

O Norte Pioneiro teve seu processo de ocupação iniciado a partir de meados do século XIX, por iniciativa de empreendedores individuais, de forma lenta e espontânea, numa área próxima à fronteira paulista, até o século $X X$, quando o povoamento começa a ser mais intenso e de forma mais regular (CANCIAN, 1981; CESÁRIO, 1991).

As primeiras entradas deram-se pelos cursos superior e médio do rio Itararé, sendo os mineiros e paulistas os primeiros a se defrontar com os indígenas que nestas terras estavam. Neste primeiro momento, segundo Cancian (1981), o forte não eram as plantações de café, pois não havia estrutura suficiente para atingir os mercados, dada a distância dos portos e a falta de estradas que ligassem as regiões consumidoras. Mesmo com a presença de terras férteis e preços favoráveis no mercado, apenas mais tarde o café passou a ser 
interessante aos lavradores. O que movimentava a economia na região nesta época era a criação e engorda de suínos. A partir de 1890, com novas picadas abertas para comércio com localidades paulistas, a região passa a ter mais estradas e ligações por portos via balsas. Nesta época era crescente também o número de fazendas, sítios e povoados que passaram a surgir, grande parte por iniciativa particular. Cesário (1991) ressalta que nesta primeira fase de expansão o que se destaca são os processos de produção e a relação entre o espaço rural e o urbano. A grande propriedade teve papel relevante no processo, no qual a fazenda tinha função de organizadora da produção. E a respeito das cidades do Norte Velho, a autora salienta que estas "[...] são apreendidas como núcleos urbanos que não chegaram a desenvolver uma estrutura administrativa e de serviços suficientemente forte que pudesse lhes conferir, atualmente, a mesma importância que hoje desfrutam as maiores cidades do estado" (CESÁRIO, 1991, p. 42).

Ao percorrer hoje os municípios do Norte Pioneiro, pode-se perceber as marcas deixadas pela dinâmica do café da época relatada por Cesário pois, dentre outras características, são pequenos municípios, com população que varia entre aproximadamente 2.300 a 48.500 habitantes (IBGE, 2019).

A cafeicultura nesta época mantinha-se muito mais ligada ao estado de São Paulo do que propriamente com o estado do Paraná. Por falta de infraestrutura, houve uma tendência natural a utilizar as condições de transporte pré-existentes e sua dependência com o estado de São Paulo para comercialização via porto de Santos. Como enfatiza Cancian (1981, p. 55): "São Paulo trouxe muito mais cedo que o Paraná a ferrovia que penetrava até ponto próximo aos cafezais, e já na década de 1920, dentro da própria zona cafeeira".

Não apenas em relação à infraestrutura esta região teve forte ligação com São Paulo: apesar de os mineiros terem se estabelecido nas últimas décadas do século XIX, a ocupação por paulistas foi a que mais se destacou. Era deles o capital investido, seja por meio de financiamentos pelos bancos paulistas ou pela venda de suas terras em São Paulo para investir no Paraná (CANCIAN, 1981).

Nessa primeira fase da cafeicultura paranaense, o que se seguia era o modelo paulista e como sequência dele, principalmente pelas baixas nos rendimentos dos velhos cafezais de São Paulo (devido às terras menos férteis, maiores custos de produção, preços baixos para venda e pouco atrativo em relação à mão-de-obra, perdendo para as novas terras). Pozzobon (2006, p. 42) relata que a organização e a administração das propriedades no Norte Pioneiro do Paraná eram similares àquelas praticadas em São Paulo, onde os "empreiteiros" conduziam a formação das lavouras nas fazendas nos primeiros 4 a 6 anos: "[...] A remuneração dos formadores e empreiteiros consistia no cultivo das culturas intercalares, nas produções iniciais do café e no trabalho extra remunerado. Recebia um 
rancho ou uma casa de madeira para moradia e uma área reservada à criação de animais domésticos. [...]"

Além da infraestrutura e da ocupação, houve influência paulista também na estrutura fundiária do Norte Velho do Paraná: fazendas compostas por grandes propriedades, em sua maioria, e ao lado existiam já pequenas propriedades de sitiantes (CANCIAN, 1981; POZZOBON, 2006). O que tornava os negócios rentáveis nestas fazendas era o fato da presença do proprietário nas terras. No Paraná, a imigração não era subvencionada, ou seja, não era custeada e não possuía nenhum incentivo do governo, e ficava a cargo dos fazendeiros as despesas. Em alguns contratos o colono ficava sempre vinculado às terras do fazendeiro e em outros o colono conseguia acumular renda a ponto de ser possível a compra de terras nas colônias de particulares que começavam a despontar a partir da década de 1920, com as companhias de colonização.

Durante o período entre 1930 e 1944, foi um período de recessão em que houve, principalmente em São Paulo, a redução da produção cafeeira pelos grandes proprietários de terras, o que deu visibilidade para o Paraná, onde os altos investimentos feitos na ocupação das terras do Norte Novo pelas empresas colonizadoras, principalmente pelo capital inglês, permitiram que a produção cafeeira tivesse continuidade, mesmo numa conjuntura recessiva. O plantio se estendeu principalmente para as pequenas propriedades (dado a participação do trabalho familiar, que diminui os custos de produção), sendo que, para as grandes, em alguns casos, houve o abandono do café (pela superprodução, aumento dos custos de produção e redução dos preços de mercado) e o investimento em outros gêneros.

Segundo Almeida (1981), apesar da atividade cafeeira ter se iniciado no Paraná entre as décadas de 1920 e 1930, é somente a partir de 1945 que esta atividade teve uma ascensão mais significativa. $O$ investimento feito pelas empresas colonizadoras em estradas fez com que o Paraná se destacasse no mercado nacional. Mesmo com o crescimento econômico desta região, o estado como um todo não estava com sua economia consolidada, pois grande parte da renda gerada no Norte se dirigia para fora do estado, devido à estreita relação com São Paulo. Grande parte da rentabilidade do café que ia para São Paulo serviu para alicerçar o desenvolvimento do setor industrial daquele estado e somente parte da renda da cafeicultura ficava no Paraná para ser reinvestida na própria agricultura. Em 1961, com a construção da "Rodovia do Café", esta realidade muda, já que esta ligou o norte do estado ao Porto de Paranaguá.

$\mathrm{Na}$ década de 1920 as maiores fazendas de café concentravam-se em Jacarezinho e Ribeirão Claro. Entre 1927 e 1931, Jacarezinho expandia o plantio de cafeeiros, sendo o centro mais dinâmico de produção e o município de Bandeirantes passou a ser uma frente 
pioneira. Entre 1932 e 1934 há uma redução de área de plantio nestas localidades, sendo que as médias e pequenas propriedades em municípios mais novos é que se destacam.

Cancian (1981) enfatiza a diferenciação na cafeicultura anterior a 1929 e aquela das áreas abertas entre 1930 e 1940. No Norte Pioneiro, onde a ocupação se fez de forma espontânea, a cultura cafeeira se fez no modelo tradicional paulista, com explorações em grandes propriedades. Já no Norte Novo, onde a colonização foi dirigida, o planejamento antecedeu a colonização e o parcelamento do solo, a venda dos lotes (pequenos e médios) e a facilidade de parcelamento do pagamento permitiu que antigos colonos e lavradores se tornassem proprietários de terras. Para estes o interesse pelo café existiu por serem antigos colonos que, transformados em proprietários, passaram a lavrar a terra junto à sua família, não tendo custos de mão de obra, morando no próprio lote, construindo sua casa e alimentando-se do que produziam. Os imigrantes estrangeiros que ali se instalaram também viviam de modo semelhante. No final da década de 1940 e em toda a década de 1950, a renda que obtinham da produção de café permitiu que muitos comprassem terras na região de Maringá e também no Norte Novíssimo. Resumindo, nesta fase, o Norte do Paraná teve uma expansão do plantio, aumento da área cultivada e quantidade de propriedades que aderiram à produção. Isso fez com que os cafezais adentrassem ainda mais para o interior do estado. Houve a redução de cafeeiros antigos, pouco produtivos, dando lugar às áreas novas, fracionamento das grandes propriedades, separação das tarefas de produção e beneficiamento, com a divisão do trabalho entre campo e cidade e diversificação agrícola.

Cesário (1991) menciona que a região norte do Paraná como um todo foi ocupada por paulistas e mineiros, em sua maioria, mas também foi atrativa para nordestinos e estrangeiros. Os descendentes de migrantes vindos de outros estados, como o caso dos paulistas, desenvolveram nas pequenas propriedades do Norte Novo um sistema agrícola baseado no trabalho familiar.

A fase mais dinâmica e de maior vitalidade da produção cafeeira no estado se dá no período pós-guerra, de 1945 a 1970 e o centro principal de produção cafeeira no país se desloca de São Paulo para o Paraná. O modelo de grandes propriedades, tradicionalmente aplicado em São Paulo, não se repete em todo o Norte do Paraná (apenas no Norte Pioneiro) devido às condições de ondulação do terreno, em que as áreas mais baixas não eram utilizadas para o plantio do café devido ao alto índice de geadas. O parcelamento do solo em pequenas e médias propriedades pelas empresas colonizadoras, em parte, foi feito de forma mais racional, respeitando as condições topográficas.

Após a euforia da década de 1950, os preços do café resultaram em políticas de erradicação de lavouras improdutivas. Com o encerramento da fase dinâmica do café, os investimentos passaram a ser em outras culturas e também para outros setores da 
economia. Inicia-se o programa de racionalização da produção e o incentivo à produção de outras culturas (POZZOBON, 2006).

Segundo Carvalho (1999, p. 135) o grupo responsável pela racionalização da cafeicultura criou dois programas de erradicação de cafezais entre 1962 e 1969, “[...] cujos objetivos eram a erradicação de cafezais antieconômicos, a modernização da cafeicultura brasileira e a substituição destes cafezais por lavouras em bases modernas". Como também salienta Carvalho (1991, p. 75), no Paraná as regiões mais afetadas por este programa foram o Norte Novo e Norte Novíssimo. As principais culturas substitutivas foram a soja, o milho, o algodão, o feijão e a pastagem. "Espacialmente, [...] a distribuição dessas lavouras substitutivas ocorreu desigualmente, com a predominância da pastagem nas regiões do Norte Novo e no Norte Novíssimo, enquanto o milho e o feijão eram as majoritárias no Norte Velho". Em ampla escala, no Brasil, como resultado deste programa de erradicação, o número de cafeeiros erradicados e áreas liberadas concentraram-se nos estados de São Paulo, Minas Gerais, Paraná e Espírito Santo.

Apesar de já ter ocorrido outras geadas fortes na região Norte do estado (como a de 1963 e a de 1969), a "geada negra" em 1975, mais precisamente em 18 de julho, foi um marco histórico na cultura do café, acelerando as transformações socioespaciais do campo norte paranaense. A erradicação dos cafezais foi a alternativa encontrada por grande parte dos produtores na época. Segundo pesquisa realizada por Niehues (2016), alguns produtores não erradicaram o café, persistindo nesta atividade e enfrentando as dificuldades pós geada. No ano seguinte não houve produção de café, então cafeicultores tiveram que buscar estratégias de subsistência até que finalizasse o ciclo de rebroto ou crescimento das plantas (dois a três anos), com o plantio para consumo e venda do excedente. Alguns cafeicultores que já tinham armazenado sacas de café em suas propriedades conseguiram comercializar a preços altíssimos devido à escassez no mercado.

$\mathrm{Na}$ atualidade, em função do aumento no consumo mundial de café e redução das áreas de produção, o café volta a ser produzido em algumas propriedades, observando-se a mudança no perfil dos produtores e também do investimento na qualidade da produção. Até o início da década de 1990 há o predomínio da agricultura convencional, ou seja, ampla utilização de máquinas e defensivos químicos. Só nas décadas mais recentes, segundo o IBGE (2016), existem iniciativas alternativas a esta forma de produção, como associação de produtores, com a visão de uma agricultura com menos impactos socioambientais: "Mesmo entre alguns médios e grandes produtores parece crescer a percepção de que a adoção de técnicas poupadoras dos recursos naturais pode trazer lucratividade não só a curto, mas também a longo prazo" (IBGE, 2016, p. 35).

Segundo dados de 2017, os maiores destaques agrícolas do Paraná são na produção de cana-de-açúcar (45 milhões de toneladas), soja (20 milhões de toneladas) e milho (19 
milhões de toneladas), todas com objetivo principal de exportação. Em termos de quantidade, o café tem uma representatividade pequena se comparado aos demais produtos agrícolas, cerca de 73 mil toneladas (INSTITUTO PARANAENSE DE DESENVOLVIMENTO ECONÔMICO E SOCIAL, 2019).

O que tem se destacado no Paraná desde 2011 (em especial na região do Norte Pioneiro) é a produção de cafés especiais. De acordo com a Associação Brasileira de Cafés Especiais (2019), os cafés especiais envolvem "[...] desde suas características físicas, como origens, variedades, cor e tamanho, até preocupações de ordem ambiental e social, como os sistemas de produção e as condições de trabalho da mão-de-obra cafeeira". A partir destes requisitos, hoje a produção cafeeira está muito mais pautada na qualidade dos grãos comercializados do que na quantidade. Devido aos cuidados que se deve ter do plantio até o beneficiamento do mesmo, o valor de venda para alguns cafés diferenciados varia entre $30 \%$ e $40 \%$ a mais em relação ao café cultivado de modo convencional.

Hoje, o Norte Pioneiro do Paraná consolidou-se como região produtora de cafés especiais do Brasil, por meio da Indicação Geográfica de Procedência (IGP). De acordo com o INPI - Instituto Nacional de Propriedade Industrial (2019), "Considera-se a Indicação de Procedência o nome geográfico de país, cidade, região ou localidade de seu território, que tenha tornado conhecido como centro de extração, produção ou fabricação de determinado produto ou de prestação de determinado serviço". A Rota do Café é composta por empreendimentos que se relacionam direta e indiretamente com estas qualidades de café, como as cafeterias que servem de variadas formas os cafés especiais e também fazendas que se dedicam à produção e beneficiamento dos grãos.

Apesar de o café não ser mais a principal atividade produtiva da região Norte do Paraná, a importância da ressignificação e do registro das memórias vinculados a esta produção permite que um tempo passado (e suas marcas nas paisagens) seja (re)valorizado pelas manifestações culturais (sejam elas materiais ou imateriais) dos empreendedores da Rota do Café.

\section{ROTA DO CAFÉ - NORTE DO PARANÁ: PAISAGENS DO CAFÉ}

A Rota do Café - Norte do Paraná abrange atualmente seis municípios do norte do estado: Londrina, Arapongas, Ibiporã, Santa Mariana, Ribeirão Claro e São Jerônimo da Serra, em um raio de distância de aproximadamente 200 quilômetros de Londrina (cidade sede da Rota). Conta hoje com empreendimentos associados e parceiros (dentre eles pousadas, cafeterias, museus, restaurantes, agroindústrias, fazendas históricas e produtivas e instituições de pesquisa, além de barista e corretor de café) que possuem relação direta ou indireta com a cultura cafeeira. 
Mesmo com a diversidade de atrativos na Rota do Café, as paisagens são mais significativas no meio rural. As paisagens rurais apresentam uma sociobiodiversidade que podem ser aproveitadas como atrativos turísticos. A região norte paranaense tem marcada em suas paisagens elementos materiais e simbólicos da época auge da economia cafeeira.

Estudos indicam que a paisagem é um dos principais elementos na escolha de um destino para viajar. Por isso a importância de estudar as paisagens. Pires (1999, p. 162) enfatiza que "[...] se a razão de ser do turismo [...] é o deslocamento ou movimento voluntário das pessoas de um lugar para outro no espaço, então o turismo pode ser concebido como uma experiência geográfica na qual a paisagem se constitui num elemento essencial".

As paisagens rurais podem proporcionar um "retorno simbólico" ao passado rural, ao mesmo tempo em que permite momentos de aprendizado, descanso e lazer. Tornam-se assim atrativos: "[...] pequenas igrejas e museus, de colheitas, festas, costumes e crenças tradicionais, romarias, artesanato e comidas típicas, valorizando os produtos específicos do local" (CALVENTE, 2004, p. 11).

Os elementos naturais e culturais que compõem as paisagens rurais podem ser considerados como patrimônio de determinada sociedade, tornando-se importantes para as pessoas que dela fazem parte, pois é na relação com o patrimônio que se ressignifica a memória de um povo. De acordo com Naranjo (2004), a primeira condição para considerar a paisagem como patrimônio reside em sua valorização social e na aceitação de que é um componente essencial do espaço vivido.

Segundo Font (1992) nossa relação sensorial com as paisagens é global e não apenas visual e, como salienta Rodrigues (1999, p. 47), "[...] ler a paisagem é muito mais complexo do que ver e perceber a paisagem". As paisagens são feitas de sons, odores e outras impressões sensoriais que vão muito além do que se vê. É importante salientar que a paisagem possui componentes objetivos e subjetivos devido aos significados contidos nela atribuídos pela sociedade por meio também da materialização de suas ações (COSGROVE, 1998).

Como forma de valorização das paisagens, o turismo apresenta-se como uma importante atividade. O significado econômico do turismo é muitas vezes evidenciado como principal força motriz para o desenvolvimento do setor, mas nem só de cifrões vive o turismo. Essa atividade também possui efeitos sociais, culturais e ambientais muito fortes nas localidades, variando de um local para outro devido à sua singularidade. Por meio do desenvolvimento da atividade turística é possível que o patrimônio da localidade seja valorizado e conservado, beneficiando tanto os residentes quanto os visitantes. Além disso, o turismo pode propiciar a recuperação de áreas degradadas e incentivar a conservação dos recursos naturais. Por outro lado, se mal planejado, o desenvolvimento da atividade pode 
acarretar em perda da identidade cultural da população local e depredação de bens patrimoniais naturais e culturais por meio da visitação sem controle, dentre outros.

O turismo, por ser uma atividade eminentemente social, é resultado de ações e desejos da sociedade como um todo que transformam as paisagens, envolvendo diversos elementos que são essenciais à sua existência, como os recursos naturais e culturais, equipamentos, serviços e infraestrutura de apoio. Esse conjunto de atividades desencadeia uma série de efeitos positivos e negativos nos locais onde ocorre, transformando suas paisagens (MILAGRES; SOUZA, 2012).

Em algumas paisagens do Norte do Paraná é possível perceber as marcas deixadas pela cafeicultura, sendo a valorização da cultura cafeeira como atrativo turístico um dos principais objetivos da Rota do Café. A seguir é possível conhecer algumas paisagens que compõem os roteiros da Rota.

Na Fazenda Palmeira, localizada em Santa Mariana, dentre as diversas paisagens de uma fazenda produtiva fundada em 1942, em paisagens como a da figura 01 é possível identificar que "Através de elementos representativos na paisagem, o passado e o presente estão reunidos no espaço - no espaço social, que é o território da sociedade" (DELAMARO et al., 2002, p. 13). A composição de elementos naturais e culturais na paisagem juntamente com informações sobre o local potencializa sua atratividade, já que permite ao visitante ter uma experiência mais completa da dinâmica local.

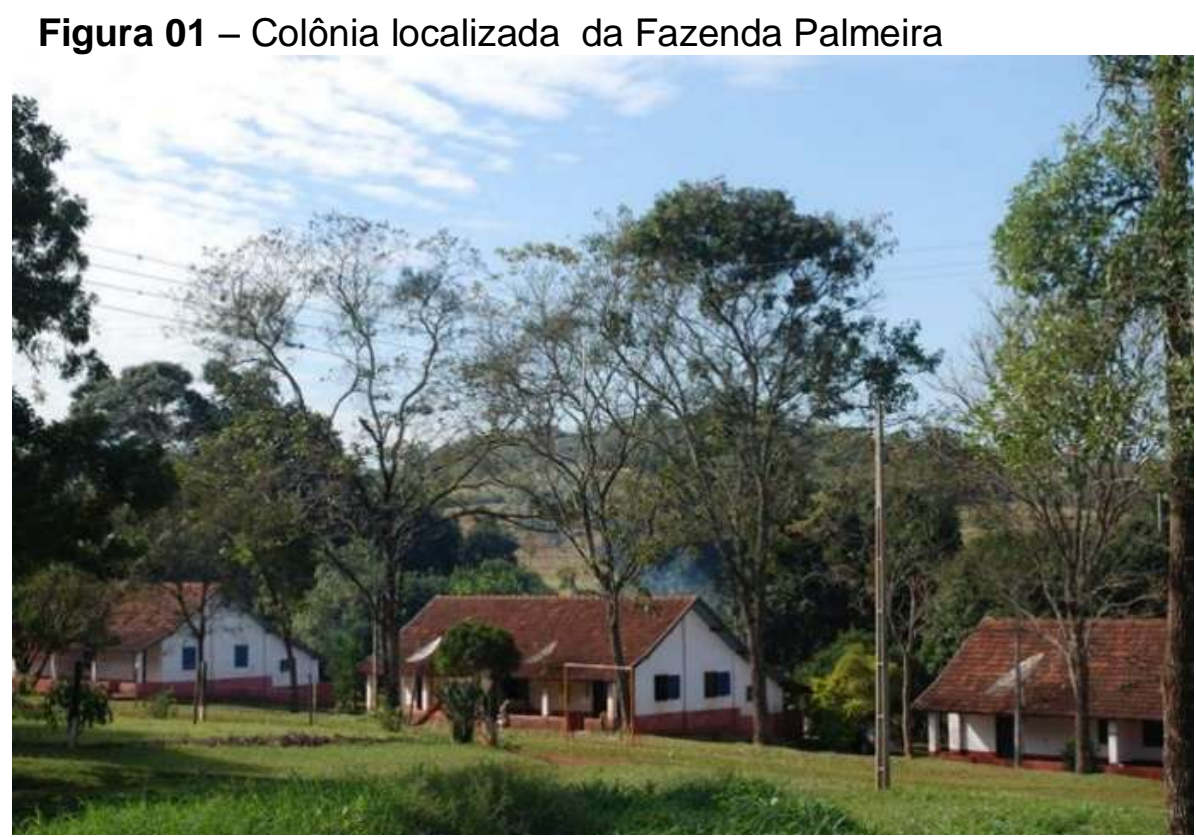

Fonte: Rota do Café (2016).

De acordo com pesquisa realizada durante trabalho de campo, moram na propriedade 29 famílias. Contando com crianças, adolescentes e idosos, a colônia chega a 82 habitantes. A fazenda emprega cerca de 30 funcionários durante o ano todo, que moram na 
fazenda com suas famílias. Durante a colheita, que demanda mais mão de obra, são contratados temporários vindos de Santa Mariana (município onde se localiza a fazenda). As mulheres da comunidade também produzem artesanato feito com taboa (cesto, portaguardanapo, cachepô, chapéu, jogo americano etc.), que podem ser comprados durante a visita ao local.

A estrutura em sequência, presente na fazenda, desde a produção na lavoura até a xícara de café permite que os visitantes conheçam os processos, sintam as sensações de participar das tarefas diárias do cafezal, conhecendo sabores, odores e sons característicos deste ambiente: o vento batendo nos pés de café, o sabor doce do café cereja colhido do pé, o aroma da "terra vermelha" molhada, os sons das máquinas de beneficiamento, os movimentos do revolvimento do café no terreiro e o que mais cada visitante consegue perceber dos momentos de interação do grupo com as paisagens locais.

Durante a colheita, o turista pode colher o café manualmente, acompanhar a colheita mecânica e secá-lo no terreiro. No restante do ano ele executa outros trabalhos como desbrota ou carpa da lavoura de café e recebe informações sobre o cultivo e os cuidados para obter um café de qualidade. Além de receber visitantes com objetivo de lazer, a fazenda tem recebido grupos de escolas com objetivo de turismo pedagógico e para isso adaptam o conteúdo à idade e às disciplinas trabalhadas em sala de aula (OLIVEIRA, 2018).

Já a Fazenda Terra Nova, localizada em São Jerônimo da Serra, é também uma fazenda produtiva, onde o visitante pode conhecer a produção a partir de técnicas diferenciadas da agricultura biodinâmica (figura 02). O destaque da fazenda Terra Nova é a produção de cafés e cereais com certificação Biodinâmica/Orgânica, cuja marca é Terrara.

As premissas da biodinâmica são as bases da produção orgânica, como a conservação dos solos e a inserção de espécies nativas de flora local, mas ela vai além. Dentre algumas características do processo, há a utilização de adubação verde, com o uso de algumas plantas que servem de nutrientes para o cafezal, como o nabo forrageiro.

A agricultura biodinâmica é um fator competitivo frente aos demais grãos produzidos de forma tradicional, pois se preocupa desde a saúde do solo, passando pelas técnicas aplicadas e pela mão de obra empregada, até a colheita e o processamento do grão para ser comercializado. Este diferencial de produção inclusive permite que o proprietário receba produtores (e também turistas "curiosos" em obter conhecimento das "coisas da terra") de diferentes lugares do Brasil e do mundo para conhecer formas alternativas de produção que minimizem os impactos ao meio. Pode-se assim enquadrar a atividade desenvolvida na fazenda como turismo rural científico-pedagógico, segundo Rodrigues (2003).

Na fazenda é realizado todo o processo de beneficiamento: para o café, a lavagem, seca, benefício, rebenefício e processo industrial com torrefação e embalagem de produtos (torrado moído e em grãos). Beneficiam também feijão preto e carioca, milho pipoca e 
farinha de trigo integral. Os cereais soja, milho e aveia são entregues em grãos para a Gebana, uma empresa de processamento e comercialização de grãos, com sede em Capanema, oeste do Paraná.

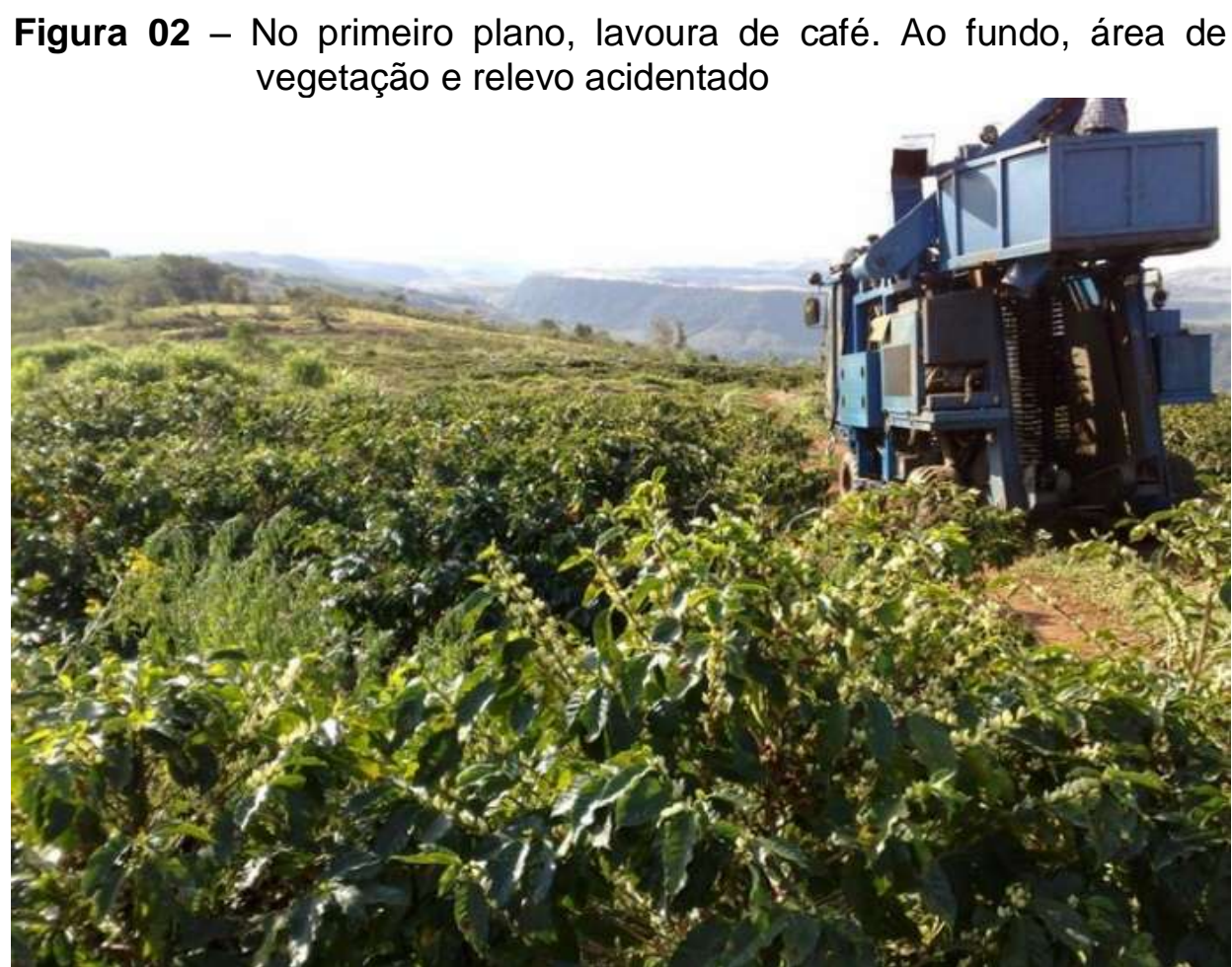

Fonte: Rota do Café (2016).

Já em Ribeirão Claro, as marcas da cafeicultura deixadas nas paisagens ilustram a dinâmica da cafeicultura no Norte Velho, por exemplo, como na Fazenda Monte Bello (figura 03), onde é possível encontrar na mesma propriedade todos os equipamentos conservados utilizados desde o plantio, até a colheita e beneficiamento do café, ou seja, o processamento ocorria por completo na fazenda.

O patrimônio material presente permite registrar a memória do café pelo que se vivenciou naquela localidade. A atratividade das paisagens é diferenciada, pois está diretamente ligada à história da propriedade, que hoje já não tem o café como principal produto. A propriedade, de cerca de 126 hectares, foi fundada no início do ano 1900 e teve o café como base de sua economia, na época em que o Norte do Paraná teve seu maior destaque na produção deste grão (a família investiu na cafeicultura até 2008, quando deram espaço a outros cultivos mais rentáveis).

Compreender as paisagens locais é fundamental para a Geografia. Nas propriedades rurais associadas à Rota do Café pode-se perceber que elas têm muito a "contar": repleta de elementos da memória do café, o visitante tem a oportunidade de conhecer os bens patrimoniais materiais e imateriais da família que compõe a história da economia regional. 
No caso da Monte Bello, um monitor (que é o gerente da fazenda) acompanha os grupos, explicando desde o plantio até a colheita e o beneficiamento do café e também fazem uma caminhada por uma trilha em meio à vegetação local.

Figura 03 - Parte da estrutura de beneficiamento do café na Fazenda Monte Bello

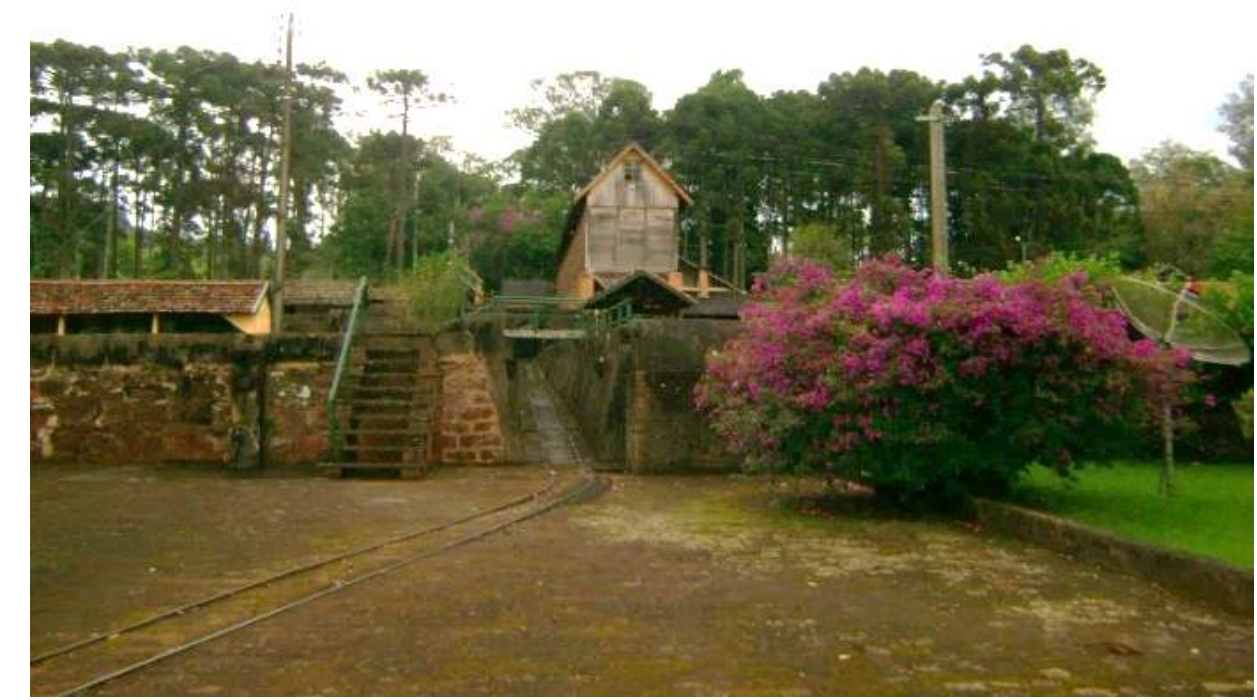

Fonte: o próprio autor (2017).

Para as manifestações ou elementos do passado que permanecem na paisagem e que sejam singulares ou alcancem a condição de elemento paisagístico significativo, é necessário reconhecê-los e estabelecer as atribuições simbólicas ou identitárias que tenham para as comunidades locais ou regionais (NARANJO, 2004).

\section{CONSIDERAÇÕES FINAIS}

O Norte do Paraná apresenta muitos elementos em que o café remete à sua história pela importância socioeconômica que exerceu. A Rota do Café tem como um dos seus objetivos permitir que estes elementos da cultura local sejam ressignificados e valorizados pela população e também pelos visitantes, para que, no caso de Londrina, além de conhecer a cidade moderna que se tornou, também possa ser evidenciado seu patrimônio, com intuito de que não seja esquecido por conta do tempo. No caso de outros municípios do Norte do Paraná ainda é possível compreender sua história e as marcas da economia do café nas paisagens, por meio da observação de monumentos, edificações, obras de arte, que podem ressignificar a memória do lugar. 
Observou-se que o desenvolvimento da atividade turística que vem ocorrendo na Rota do Café tem proporcionado aos visitantes uma oportunidade de envolvimento com as paisagens locais e conhecimento da história e dos atrativos naturais e culturais do norte do Paraná, ligados direta e indiretamente à cultura cafeeira.

Outro motivo pelo qual a Rota do Café é importante na região norte do Paraná é dar espaço para uma "nova" atividade agrícola que vem despontando, que é a produção de cafés especiais, cuja qualidade dos grãos e consequentemente da bebida complementa a atratividade da região, já que parte do público que visita a região busca conhecer os métodos diferenciados de cultivo do café, como o café biodinâmico da Fazenda Terra Nova ou a sistemática produção em escala, na Fazenda Palmeira.

Ao passo que o café volta a ser valorizado (tanto a comercialização do grão para mercado interno e externo quanto a bebida e derivados) afloram os elementos que fizeram parte do cotidiano de muitas famílias que por aqui residem ou residiram. Além disso, a região norte do Paraná apresenta paisagens com elementos naturais de beleza cênica que atraem visitantes, motivados pelo contato com elementos do ambiente natural e também com as atividades do campo.

\section{REFERÊNCIAS}

ALMEIDA, A. M. C. de. Participação social dos operários de origem rural em área urbana - Londrina/PR. Curitiba: Grafipar, 1981.

ASSOCIAÇÃO BRASILEIRA DE CAFÉS ESPECIAIS. Varginha, MG: BSCA, 2019. O que são cafés especiais. Disponível em: http://bsca.com.br/cafes-especiais.php. Acesso em: 5 jul. 2019.

BRASIL. Ministério da Agricultura, Pecuária e Abastecimento. Café no Brasil. Brasília: MAPA, 2017. Disponível em: https://www.gov.br/agricultura/pt-br/assuntos/politicaagricola/cafe/cafeicultura-brasileira. Acesso em: 5 jul. 2019.

CALVENTE, M. del C. M. H. Turismo e excursionismo rural: potencialidades, regulação e impactos. Londrina: Humanidades, 2004.

CANCIAN, N. A. Cafeicultura paranaense: 1900/1970. Curitiba: Grafipar, 1981.

CARVALHO, M. S. de. A pequena produção de café no Paraná. 1991. Tese (Doutorado em Geografia Humana) - Universidade de São Paulo, São Paulo, 1991.

CARVALHO, M. S. de. O uso do solo na década de 1960 no norte do Paraná e a política cafeeira. Geografia, Londrina, v. 8, n. 2, p. 135-141, jul. /dez. 1999.

CESÁRIO, A. C. C. Norte novo: a expansão da fronteira e seu conteúdo simbólico. In: PAZ, F. M. (org.). Cenários de econômica e política: Paraná. Curitiba: Prephacio, 1991. p. 41 63.

COMPANHIA NACIONAL DE ABASTECIMENTO - CONAB. Safras. Séries Históricas. Café total: parque cafeeiro. Disponível em: www.conab.gov.br/info-agro/safras/serie-historicadas-safras. Acesso em: 5 jul. 2019.

CONSELHO DOS EXPORTADORES DE CAFÉ DO BRASIL - CECAFÉ. Consumo interno: Brasil: consumo interno de café em sacas e per-capita. São Paulo, SP: CECAFÉ, 2019. 
Disponível em: www.cecafe.com.br/dados-estatisticos/consumo-interno/. Acesso em: 5 jul. 2019.

COSGROVE, D. A geografia está em toda parte: cultura e simbolismo nas paisagens humanas. In: ROSENDAHL, Z.; CORRÊA, R. L. (org.). Paisagem, tempo e cultura. Rio de Janeiro: EDUERJ, 1998. p. 92-122.

DELAMARO, M. C. et al. Turismo nas fazendas históricas do Vale do Paraíba Fluminense: um estudo sobre sustentabilidade.

DELAMARO, M. C.; SAVIOLO, S.; OLIVEIRA SANTOS, J. H. de; BURSZTYN, I.;

DELAMARO, L. D. S. L.; D'OLIVEIRA, E.; MUDADO, T. Turismo nas fazendas históricas do Vale do Paraíba Fluminense: um estudo sobre sustentabilidade. Caderno Virtual de Turismo, Niterói, RJ, v. 2, n. 4, p. 11-17, 2002.

EMBRAPA. Brasil: maior produtor mundial de café: exporta 35,15 milhões de sacas com média mensal de 2,92 milhões de sacas em 2018. Brasília, DF: Embrapa Café, 2019. Disponível em: www.embrapa.br/busca-de-noticias/-/noticia/41551077/brasil---maiorprodutor-mundial-de-cafe---exporta-3515-milhoes-de-sacas-com-media-mensal-de-292milhoes-de-sacas-em-2018. Acesso em: 5 jul. 2019.

EMBRAPA. Café é a segunda bebida mais consumida no Brasil. Brasília, DF: Embrapa Café, 2015. Disponível em: www.embrapa.br/busca-de-noticias/-/noticia/2574254/cafe-e-asegunda-bebida-mais-consumida-no-brasil. Acesso em: 5 jul. 2019.

FONT, J. N. Turismo, percepción del paisaje y planificación del território. Estudios Turísticos, Madrid, n. 115, p. 45-54, 1992.

FREDERICO, S. Globalização, competitividade e regionalização: a cafeicultura científica globalizada no território brasileiro. GEOUSP: Espaço e Tempo (Online), São Paulo, v. 18, n. 1, p. 55-70, 2014. Disponível em: www.revistas.usp.br/geousp/article/view/81077. Acesso em: 4 set. 2016.

HOFF, S. A ocupação do Norte. In: PAZ, F. M. (org.). Cenários de econômica e política: Paraná. Curitiba: Prephacio, 1991. p. 25-39.

IBGE. A Geografia do café: dinâmica territorial da produção agropecuária. Rio de Janeiro: IBGE, 2016.

IBGE. Cidades. Conheça cidades e Estados do Brasil. Disponível em: https://cidades.ibge.gov.br/v4. Acesso em: 5 jul. 2019.

INSTITUTO NACIONAL DA PROPRIEDADE INDUSTRIAL - INPI. Guia básico de indicação geográfica. Disponível em: https://www.gov.br/inpi/pt-br/servicos/indicacoesgeograficas/guia-basico. Acesso em: 5 jul. 2019.

INSTITUTO PARANAENSE DE DESENVOLVIMENTO ECONÔMICO E SOCIAL IPARDES. Área, produção e produtividade dos principais produtos agrícolas do Paraná - 1986 - 2019. Curitiba, PR: IPARDES, 2019. Disponível em: www.ipardes.gov.br/pdf/indices/produtos_agricolas.pdf. Acesso em: 5 jul. 2019.

MILAGRES, V. R.; SOUZA, L. B. Ensaio sobre a paisagem e o turismo: uma viagem além das disciplinas. Geografia, Londrina, v. 21, n. 1, p. 37-63, jan. /abr., 2012.

NARANJO, F. Z. El paisaje, patrimonio público y recurso para la mejora de la democracia.Patrimônio Histórico, Sevilha, n. 50, p. 66-73, out. 2004. Disponível em: www.iaph.es/revistaph/index.p hp/revistaph/article/view/1821/1821\#.V_uZgPkrLIU. Acesso em: 5 jul. 2019.

NIEHUES, L. G. A cafeicultura na microrregião geográfica de Londrina (PR): desafios e perspectivas à permanência do produtor familiar. 2016. Dissertação (Mestrado em Geografia) - Universidade Estadual de Londrina, Londrina, 2016. 
OLIVEIRA, A. N. de. A paisagem e o patrimônio como atrativos turísticos: a rota do Café - norte do Paraná. 2018. Tese (Doutorado em Geografia) - Universidade Estadual de Londrina, Londrina, 2018.

ORTEGA, A. C.; JESUS, C. M. Território, certificação de procedência e a busca da singularidade: o caso do café do cerrado. Política \& Sociedade, Florianópolis, SC, v. 10, p. 305-330, 2011.

PADIS, P. C. Formação de uma economia periférica : o caso do Paraná. Curitiba: Ipardes, 2006.

PIRES, P. dos S. Paisagem litorânea de Santa Catarina como recurso turístico. In: YÁZIGI, E.; CARLOS, A. F. A.; CRUZ, R. de C. A. da (org.). Turismo: espaço, paisagem e cultura. São Paulo: Hucitec, 1999. p. 161-177.

POZZOBON, I. A epopeia do café no Paraná. Londrina: Grafmarke, 2006.

RODRIGUES, A. B. Paisagem, território e empreendedorismo: pilares do desenvolvimento do turismo de base local. Aportes Y Transferencias, Mar del Plata, ano 7, v. 2, p. 10-40, 2003.

RODRIGUES, A. B. Turismo e espaço: rumo a um conhecimento transdisciplinar. São Paulo: Hucitec, 1999.

ROSANELI, A. F. Cidades novas do café: história, morfologia e paisagem urbana. Curitiba: UFPR, 2013.

ROTA DO CAFÉ. Pontos Turísticos. Disponível em: www.rotadocafe.tur.br/rota-do-cafe.html. Acesso em: 15 jul. 2016.

SANTOS, M.; SILVEIRA, M. L. O Brasil: território e sociedade no início do século XXI. Rio de Janeiro: Record, 2005.

Recebido: novembro de 2019. Aceito: abril de 2020. 